\title{
A Review: Antibacterial activities, antioxidant properties and toxicity profile of centella asiatica
}

\author{
Suzita Ramli ${ }^{*}$, Wong Jun Xian ${ }^{1} \&$ Noor Azira Abd Mutalib ${ }^{2}$ \\ ${ }^{1}$ Department of Biology, Faculty of Science and Mathematics, \\ Sultan Idris Education University, Tanjung Malim, Perak, Malaysia \\ ${ }^{2}$ Department of Food Service and Management, Faculty of Food Science and Technology, \\ Universiti Putra Malaysia, Serdang, Selangor, Malaysia \\ *Corresponding author: $\underline{\text { suzita@ fsmt.upsi.edu.my }}$
}

DOI: https://doi.org/10.37134/ejsmt.vol7.1.5.2020

Received: 02 January 2020; Accepted: 18 May 2020; Published: 24 May 2020

\begin{abstract}
Centella asiatica (C. asiatica) has been widely used as traditional or alternative medicine for thousand years due to its capabilities to cure various kinds of diseases. This plant has been used widely to prepare numerous kinds of food and beverages in many countries due to its beneficial functional properties. Active compounds that contribute to its antimicrobial properties are madecassic acid, asiatic acid, madecassoside, and asiaticoside. C. asiatica extract can inhibit majorities of foodborne pathogenic and spoilage microorganisms. It also contained antioxidant properties and has been proven to have an insignificant toxicity effect on human consumption. Currently, there is an increase of interest in research development for natural antioxidants and antimicrobial agents to replace the synthetic types in the food industry. This review presents information on the antioxidant capabilities of $C$. asiatica and its function to inhibit, reduce or minimize microbial growth. The toxicity and safety aspects of consuming $C$. asiatica extract has also been highlighted to provide essential data for the development of natural preservatives.
\end{abstract}

Keywords Centella asiatica, chemical composition, antioxidant capacity, antimicrobial activity, toxicity

\section{INTRODUCTION}

Centella asiatica ( $C$. asiatica) is a small creeping perennial herbaceous plant that belongs to the family of Apiaceae (Umbelliferae). It is known as 'pegaga' in Malaysia while Indian and European called it as Asian Pennywort and Gotu Kola, respectively [1,2]. C. asiatica is also a traditional medicinal herb that can be consumed either fresh or in dry form by local communities for certain countries. Stems and leaves are the most popular parts to be used as traditional drugs. Besides, it has also been claimed to have certain medicinal functions such as blood pressure reductions, cure kidney diseases, and wound healing [1-3]. There are a variety of antimicrobial agents and antibiotics drugs which act as the food preservative or additive in the current food industry. They have been used to improve food quality or food safety purposes during food preparation. Unfortunately, the usage of synthetic antimicrobial agents or antibiotics drugs can cause the evolvement of resistant microorganism strain towards certain types of medicine or drugs. Moreover, overconsumption of synthetic additives or preservatives will cause long-term or short-term side effects on our health.

Consumers nowadays emphasized more on their healthy diet and lifestyle. Synthetic additives have been restricted to be used in the food industry since they can be carcinogenic if overly-consumed [4]. Therefore, the usage of synthetic antioxidants or preservatives such as butylated hydroxytoluene (BHT) and butylated hydroxyanisole (BHA) has become a major concern for consumer health. Thus, natural preservatives should be encouraged to develop more by using natural plant extracts for consumer's health. Recently, researchers are highly interested in developing natural plant-based additives as a substitute for artificial additives [5]. Antioxidants compounds can be obtained from natural resources, basically available from any parts of plants like flowers, roots, fruits, and stems [4]. 
This review will discuss on antioxidant and antimicrobial properties of $C$. asiatica extract. Furthermore, the focus is given on suitable type of extraction solvent and concentration to achieve the optimum results for the antioxidant and antimicrobial test. In future studies, this information may help for the application of $C$. asiatica extract as an alternative food preservative to minimize the enzymatic browning issues on fresh-cut fruits and vegetables.

\section{BOTANICAL DESCRIPTION OF C. asiatica}

Based on the Malaysian Herbal Monograph, C. asiatica was defined as the herbaceous plant which consists of round apex leaves, with deeply cordate stipulate and petioles, usually at around $20 \mathrm{~cm}$ height [6]. $C$. asiatica belongs to Apiaceae family, also known as Umbelliferae. This kind of small perennial creeping plant was found indigenous to China, Australia, Madagascar, Southern United States, and Southeast Asian countries [1-2,7]. It can grow either in tropical or temperate swampy areas with attaining height from 15 to $25 \mathrm{~cm}(6-10 \mathrm{in})$. The roots grow vertically downwards with nodes. The plant has appeared either green or reddish-green colour. The plant has long green stalk with rounded apices which provide a smooth texture with leaves of palmately netted veins. The leaves are connected with 2 to $6 \mathrm{~cm}(0.79 \mathrm{in})$ long of pericardial petioles. The flowers are small (less than $3 \mathrm{~mm}, 0.12 \mathrm{in}$ ) with round umbels and each umbel contains three to four flowers. The flowers consist of white, red, pink, or purple colours $[8,9]$.

The difference between terpenoid composition is highly depending on the different parts of $C$. asiatica. It was reported that the triterpene showed the highest amount on the leaves part, followed by roots and the least was the petiole [6]. In Malaysia, there are two phenotypes of $C$. asiatica, which are smooth leaves and fringe leaves $[6,10]$. The differences between both phenotypes are shown in Table 1.

Table 1 Differences between characteristics of C. asiatica, smooth leaves and fringe leaves phenotypes

\begin{tabular}{lll}
\hline \multicolumn{1}{c}{ Phenotypes } & \multicolumn{1}{c}{ Smooth leaves } & \multicolumn{1}{c}{ Fringe leaves } \\
\hline Stolon length & $\begin{array}{l}\text { Shorter between the roots } \\
\text { connections }\end{array}$ & $\begin{array}{l}\text { Longer between the roots } \\
\text { connections }\end{array}$ \\
Overall triterpene amounts & $\begin{array}{l}\text { Higher compositions of the } \\
\text { madecassoside and asiaticoside } \\
\text { Non-detectable on roots } \\
\text { structures }\end{array}$ & $\begin{array}{l}\text { Lower compositions of the } \\
\text { madecassoside and asiaticoside } \\
\text { Low content of asiaticoside on } \\
\text { Triterpene amounts (roots) }\end{array}$ \\
Triterpene amounts (petioles) & Higher on leaves petioles & \begin{tabular}{l} 
Lower on leaves petioles \\
\hline
\end{tabular}
\end{tabular}
The information was adapted from sources of [2] and [7].

Besides C. asiatica, C. cordifolia and C. erecta are two other related species, classified under Centella genus as well. Both of them are closely related species to $C$. asiatica. They can be found in tropical or subtropical regions of North and South of the United States, Africa, and Asia. These three species are difficult to differentiate morphologically without a higher level of taxonomy experience [11]. The differences between the three Centella species are categorized in Table 2.

Table 2 Morphological differences between $C$. asiatica and its closely related species, C. cordifolia and C. erecta

\begin{tabular}{|c|c|c|c|}
\hline Species & C. asiatica & C. cordifolia & C. erecta \\
\hline $\begin{array}{l}\text { Stems } \\
\text { growing behavior }\end{array}$ & $\begin{array}{l}\text { Grow along the soil } \\
\text { surface }\end{array}$ & $\begin{array}{l}\text { Embedded very deeply in } \\
\text { the soil }\end{array}$ & $\begin{array}{l}\text { Embedded very deeply in } \\
\text { the soil }\end{array}$ \\
\hline Stems texture & Thin and fragile & Thick and hard & Thick and hard \\
\hline $\begin{array}{l}\text { Leaves surface } \\
\text { area }\end{array}$ & 6.78 to $7.83 \mathrm{~cm}^{2}$ & 11.90 to $16.92 \mathrm{~cm}^{2}$ & 22.40 to $42.20 \mathrm{~cm}^{2}$ \\
\hline Leaves shape & Cordate blade-shaped & Cordate blade-shaped & $\begin{array}{l}\text { Reniform shaped with a } \\
\text { smooth glossy texture }\end{array}$ \\
\hline Leaves margin & More dentate or crenate & More dentate or crenate & Less dentate \\
\hline
\end{tabular}

The information was adapted from the source of [11]. 


\section{C. asiatica AS FOOD AND BEVERAGE}

Other than having medicinal properties, $C$. asiatica is very useful in food and beverage industries because the whole plant units, from leaves to roots, are $100 \%$ usable and edible [1,11]. Sri Lanka people tend to use the plants to cook porridge and feed pre-school children as breakfast to deal with malnutrition from past generations. The porridge has been known as 'Gotu kola kenda' by the local community, a typical herbal mix of rice and greens $[9,12]$. 'Gotu kola sembola' is another Sri Lanka local food which can be prepared by cutting $C$. asiatica until finely then mixed with shredded coconut flakes, red onions, and seasoning spices [9].

In Malaysia and Indonesia, $C$. asiatica is commonly consumed in either fresh, cooked or dry forms. It is gaining popularity, especially in Malay and Javanese communities. It can be consumed as fresh vegetables or salad ('ulam'). The salad can be served as main meal or appetizer. Some people prefer to blend the leaves part into drinks or juices. Nevertheless, it can be cooked into soup or other main dishes. However, people are usually served together with coconut milk or shredded coconut due to the mild bitterness of $C$. asiatica. Some people prefer to add sweet potatoes or potatoes instead of coconut milk. In some local markets, the unprocessed plants can directly use to prepare herbal tea, tonic drinks, or blended into ready to drink fresh juices $[1,9]$.

Herbal tea is a local consumption practice by Thailand and India people. The herbal tea will be prepared by adding small pieces of dried and fresh leaves into boiled water [9,12]. Such tea can retained an appreciable amount of madecassic acid, asiatic acid, madecassoside, and asiaticoside compared to other consuming methods [13]. However, non heat-treated herbal tea contained more active compounds (11 to $17 \%)$ than heat-treated herbal tea $[12,13]$. In addition, freshly prepared beverages were reported to contain a large amount of volatile antioxidants compounds rather than heat treated beverages [14].

\section{C. asiatica AS TRADITIONAL REMEDY}

C. asiatica also plays an important role as a traditional remedy to treat certain diseases. Consumption of the whole plant together with chickweed and creeping wood sorrel is able to combat dysentery. Other types of traditional remedies derive from $C$. asiatica are including leaf powder, medical ointment, and leaf syrup or juices, depending on the target sickness to be treated [9].

C. asiatica powdered leaves can be grounded into paste form for directly apply or used to make ointment paste and liquid extract. They can be used for both internal or external purposes. C. asiatica's powder can be applied to cure ozaena, sore throat, ulcers, burns, leprosy, and scrofula by sprinkling the powder onto ulcers or sore throat area. Some people mix powder of $C$. asiatica with lime to treat sores for babies, with the suggested amount of three to five doses per day. Also, consuming around $1.5 \mathrm{~g}$ of dried leaves or powdered leaves per day can calm the nerves $[9,15]$. The ointment or poultice can be prepared by adding Vaseline or clarified butter into the leaves' powder. The ointment can be applied externally on the affected skin area to treat enlarged scrotum or elephantiasis. For the liquid extract, it can be consumed around one to five drops with three servings per day [9]. Furthermore, the leaf juices can deal with pain effectively by taking orally twice per day $(10 \mathrm{~mL}$ per serving). Besides pain relief, leaves juice can combat skin irritation caused by heat prickles. Palm sugar can be added during leaf juice preparation as a tonic drink for woman after baby delivery [9].

\section{C. asiatica's CHEMICAL COMPOSITION}

According to the previous review, triterpene or terpenoids compounds are the main biologically active components to promote the antioxidant properties of $C$. asiatica [16]. The triterpene compounds contribute approximately $10 \%$ of the plant content. Besides that, the antioxidant activity in $C$. asiatica (84\%) is comparable to ascorbic acid (88\%) and grape seed extract (83\%) [1]. It was discovered that $C$. asiatica can achieve $83.0 \%$ [17] and $65.7 \%$ [3] of free radicals scavenging inhibitor at a concentration of $1.00 \mathrm{mg} / \mathrm{mL}$. 
C. asiatica extract is known to contain significant amounts of asiaticoside $(1.97 \pm 2.65 \mathrm{mg} / \mathrm{mL})$ and madecassoside $(3.10 \pm 4.58 \mathrm{mg} / \mathrm{mL})$ [17]. However, the amount of asiatic acid $(0.55 \pm 0.89 \mathrm{mg} / \mathrm{mL})$ and madecassic acid $(0.55 \pm 2.29 \mathrm{mg} / \mathrm{mL})$ were pretty low. The enhancement of antioxidant activity of $C$. asiatica may contribute by asiaticoside content and flavonoid content [18]. In addition, there is no fixed triterpenes concentration due to the diverse planting locations and environmental conditions $[1,4,19]$. The ethanolic extract was also found to yield a significant amount of asiaticoside $(42.85 \mathrm{mg} / \mathrm{g})$ and madecassoside $(18.86 \mathrm{mg} / \mathrm{g})$ [3].

Previous authors had reported that the total phenolic contents of $C$. asiatica (expressed as gallic acid equivalents, GAE) was ranged between $98.50 \mathrm{mg} \mathrm{GAE} / \mathrm{g}$ to $183.24 \mathrm{mg} \mathrm{GAE} / \mathrm{g}[20,21]$. The differences of total phenolic contents are probably due to several reasons: complexity of functional groups compounds, extraction method or solvent chosen, planting and harvesting location, parts used to conduct analysis, weather, storage condition, and plant species [19]. Moreover, total phenolic contents of $C$. asiatica had been found different from leaves ( 8.13 to $11.7 \mathrm{~g} / 100 \mathrm{~g}$ ), roots $(6.46$ to $10.5 \mathrm{~g} / 100 \mathrm{~g})$, and petioles (3.23 to 4.91 $\mathrm{g} / 100 \mathrm{~g})[4]$.

\section{ANTIOXIDANT CAPACITY}

Oxidative stress can happened due to an imbalance between production of antioxidants and oxidants, which results in cell damage by releasing reactive oxygen species (ROS). Several ROS examples include superoxide radicals, hydroxyl ions, peroxide, and nitric oxide radicals which caused pathophysiological states such as cancer, aging, inflammatory conditions, or cardiovascular diseases. Antioxidants agents are free radicals scavenging materials to avoid the human body from free radicals and ROS effects $[11,18]$. The polyphenol compounds and flavonoids are readily available in $C$. asiatica to perform a better antioxidant activity, especially the leaves since it contains the highest phenolic compounds [15].

Previous published report proved that antioxidative activity and total phenolic contents are strongly correlated $\left(r^{2}=0.90\right)[4]$. The results had indicated that phenolic compounds are positively contributed to the antioxidative of $C$. asiatica. The antioxidative properties of pineapples, apples, and vegetable juices were also discovered to be heavily dependent on the phenolic compounds [21, 22]. Antioxidant activity of Malaysia plants have superior free radicals scavenging activities if using ethanolic extracts and it is correlated to the total phenolic content of plants [23,24]. In addition, extraction methods and types of solvent may affect the level of $C$. asiatica antioxidant properties. Ethanol solvent was showing the highest antioxidant activities compared to water, chloroform, methanol, and light petroleum $[23,25]$. Recent studies have reported that the optimum extraction concentration for $C$. asiatica was by soaking the sample in $40 \%$ of ethanol for $60 \mathrm{~min}$ in a solid to solvent ratio of 1:15 [1,8,26]. The consumption of $C$. asiatica extract is safe and effective to improve the body's immune system against the free radicals and maintain the oxidative stress in a balanced state. Among all triterpene compounds, asiaticoside is the most important to contribute to the early phase of wound healing. $C$. asiatica leaves are discovered to have an optimum antioxidative activity in three pathways, which consisted of superoxide free radical activity (86.4\%), free radical scavenging activity, DPPH (92.7\%), and linoleic acid peroxidation (98.2\%) [1].

An in-vitro study which conducted using the linolenic acid model also revealed ethanolic extract of C. asiatica showed a significant antioxidant capability than water and petroleum extract [23]. The roots part has performed the highest antioxidative activities compared to leaves and petioles. Other than triterpenoid compounds, the antioxidant ability was contributed by flavonoids compounds to improve cell rejuvenation and physical health. The free radical scavenging activity for $C$. asiatica extract achieved $\mathrm{IC}_{50}$ value of 31.2 $\mu \mathrm{g} / \mathrm{mL}$, whereas ascorbic acid and BHT showed $\mathrm{IC}_{50}$ values of $2.5 \mu \mathrm{g} / \mathrm{mL}$ and $7.6 \mu \mathrm{g} / \mathrm{mL}$, respectively [27]. Inhibitory concentration, $\left(\mathrm{IC}_{50}\right)$ value is defined as that the desired concentration of antioxidants required to achieve 50\% inhibition of free radicals in the specific time given. The lower the IC value, the better the antioxidant activity of plant extract can be obtained [28]. The maximum $\mathrm{IC}_{50}$ value threshold to exhibit the best antioxidant activity must range between $10 \mu \mathrm{g} / \mathrm{mL}$ to $50 \mu \mathrm{g} / \mathrm{mL}$. This proved that $C$. asiatica extract 
can scavenge the free radicals due to its phenolic $(2.9 \mathrm{~g}$ per $100 \mathrm{~g})$ and flavonoids compound $(0.36 \mathrm{~g}$ per $100 \mathrm{~g})[27,29-30]$.

Nevertheless, a research was conducted by using a lymphoma bearing mice and fed them with 50 $\mathrm{mg} / \mathrm{kg}$ of $C$. asiatica methanolic extract for 14 days continuously. The production of the antioxidant enzyme (catalase, glutathione peroxidase, and superoxide dismutase) and reduced antioxidants (ascorbic acid and glutathione) was significantly increased. A decrease of oxidative stress was observed by feeding 25 weeks of $C$. asiatica powder. This indicated the reduction of lipid peroxidation and a decrease of superoxidase dismutase activities in these mice bodies. The protective effect by $C$. asiatica plant had successfully shown a reduction in oxidative stress in mice [15].

Furthermore, the total phenolic contents and antioxidant properties are the main factors for $C$. asiatica's product to sustain for a prolonged storage period. There is an inconsistent decrease in total phenolic content was observed in pennywort and commercial ice creams throughout the 28 days of storage period. However, pennywort ice cream showed higher TPC values (172.31 to $44.03 \mathrm{GAE} \mathrm{mg} / 100 \mathrm{~mL}$ ) compared to commercial ice cream (170.02 to $38.15 \mathrm{GAE} \mathrm{mg} / 100 \mathrm{~mL})$ throughout the 28 days. ABTS antioxidant assay proved that pennywort ice cream was better than commercial ice cream and able to store longer throughout the 4 weeks storage periods [31].

\section{ANTIMICROBIAL PROPERTIES}

Antimicrobial compounds are important biological agents to inhibit and reduce the growth of microorganisms. Triterpene compounds are responsible for the antimicrobial activity of $C$. asiatica. Some of the foodborne bacteria such as Listeria monocytogenes and Bacillus cereus are still able to survive and grow under natural preservation such as freezing, salting, or pickling [32]. The previous studies demonstrated that the bacteria which inhibited by C. asiatica were Listeria monocytogenes, Bacillus cereus, Salmonella enterica serovar Enteritidis, and serovar Typhimurium, Aspergillus niger, and Candida albicans $[2,32-33]$.

Ethanolic extract of $C$. asiatica was reported to show the largest inhibition zone against Aspergillus niger (17.5 mm and $12.1 \mathrm{~mm}$ using $100 \%$ and $70 \%$ concentration of ethanol extract, respectively) and Bacillus subtilis (16.4 mm and $12.2 \mathrm{~mm}$ using $100 \%$ and $70 \%$ concentration of ethanol extract, respectively) via disc diffusion method [33]. Moreover, the ethanolic extract of $C$. asiatica could achieve $10.0 \mathrm{~mm}$ and $9.0 \mathrm{~mm}$ zone of inhibition against Staphylococcus aureus and Escherichia coli, respectively through disc diffusion method [2]. On the other hand, the ethanolic extract of $C$. asiatica was able to exhibit $7.2 \mathrm{~mm}$ and $8.2 \mathrm{~mm}$ of zone inhibition against Aspergillus flavus and Candida albicans, respectively.

C. asiatica has been promoted as a potential candidate for antimicrobial agents due to the presence of triterpenes polar compounds, which capable to combine with polyphenols adsorption on microbial membranes [33]. Microbial growth will be inhibited since their membrane has been disrupted and weakened, followed by dissolving the microbial cell wall [32,34-35]. It is also suggested that using 95\% of C. asiatica's ethanolic extract can exhibit the most desired antimicrobial capability against different enteric pathogens such as Bacillus cereus and Listeria monocytogenes under normal condition [31,35]. The concentration of ethanolic extract is known as directly proportional to the antibacterial properties of sample extract.

\section{SAFETY AND TOXICOLOGY ANALYSIS}

Toxicity is an interaction between selective toxicants and living cells to determine the extent of adverse health effects on living organisms. The experimental screening of plant extract's toxicity is very crucial to ensure the safety and effectiveness of the samples. During the past 30 years, toxicity evaluations of plant materials are frequently detected via brine shrimp lethality assay (BSLA). BSLA was designed for toxicity testing of different concentrations of crude plant extracts [36,37]. Brine shrimp (Artemia salina) was 
selected for being simple, inexpensive, rapid, convenient, and required a small amount of test material. $A$. salina was extensively studied and represent over $90 \%$ of the BSLA studies among Artemia species. BSLA has been widely used in the screening of toxicity of plant extracts $[29,37] . \mathrm{LD}_{50}$ is known as the lethal concentration required to obtain $50 \%$ death of the test population with the BSLA. The extract with below $1000 \mu \mathrm{g} / \mathrm{ml}$ is found highly toxic, 500 to $1000 \mu \mathrm{g} / \mathrm{mL}$ as low toxic and non-toxic as $\mathrm{LD}_{50}$ is above 1000 $\mu \mathrm{g} / \mathrm{ml}[37]$.

According to previous study, the cytotoxic activities of $C$. asiatica ranged between $500 \mu \mathrm{g} / \mathrm{mL}$ to more than $1000 \mu \mathrm{g} / \mathrm{mL}$, indicating that $C$. asiatica have low or insignificant cytotoxic activity [37-41]. $\mathrm{LD}_{50}$ for $C$. asiatica using ethanolic extract was discovered to be found more than $1000 \mu \mathrm{g} / \mathrm{mL}$ at three different concentrations $C$. asiatica $(100,500$, and $1000 \mu \mathrm{g} / \mathrm{mL})$ against potassium dichromate $(28.7 \mu \mathrm{g} / \mathrm{mL})$ [38]. Previous findings also indicated all concentrations posed an insignificant toxicity level after $24 \mathrm{~h}$ of exposure. Besides, the mortality rate of brine shrimp was found to be $3.33 \%, 20.00 \%$, and $40.00 \%$ at the concentration of 10,100 , and $1000 \mu \mathrm{g} / \mathrm{ml}$ of ethanolic extract of $C$. asiatica, respectively after 24 h exposure [39]. The $\mathrm{LD}_{50}$ calculated as $1926 \mu \mathrm{g} / \mathrm{ml}$ against etoposide (standard drug) showed value of $7.463 \mu \mathrm{g} / \mathrm{mL}$. The maximum and minimum limit of toxic concentration was recorded as $60,822 \mu \mathrm{g} / \mathrm{mL}$ and $606 \mu \mathrm{g} / \mathrm{mL}$, respectively, which indicated lower cytotoxicity level of $C$. asiatica. There was report showing that $\mathrm{LD}_{50}$ of $840 \mu \mathrm{g} / \mathrm{mL}$ and $765 \mu \mathrm{g} / \mathrm{mL}$ was found for $C$. asiatica using aqueous extract and chloroform extract, respectively, which showed a low toxic level of in $C$. asiatica [40]. This demonstrated that, there is a significant difference in obtaining $\mathrm{LD}_{50}$ results from different solvents' extracts. This happened due to, different solvents have different extraction potential for toxicity screening. In addition, some selective solvents are discovered as a poor medium to obtain specific bioactive compounds from plant samples which responsible for toxicity than other solvents [41]. The preparation of stock solutions and dilution factors of sample extracts may increase or decrease concentrations of sample solutions, which allows affecting the toxicity results of sample extracts directly during biological screening [37].

The efficacy, performance, and safety of $C$. asiatica has been witnessed and widely applied into traditional Indian, Asian and Chinese medicines, herbs or food and beverage, and pharmaceutical products [1]. According to the World Health Organization (WHO), the recommended oral intake of C. asiatica is 1.00 to $2.00 \mathrm{~g}$ per day for scar surface or wound healing while the recommended dosage for a dried plant is between $0.33-0.68 \mathrm{~g}$ per meal for tea or juice making $[1,42]$. To date, none toxic effects by $C$. asiatica intake being reported by the WHO [42]. The oral administration of $C$. asiatica extracts and asiatic acid were applied using experimental hamster and rabbit model. No toxicity effect has been observed after $1.0 \mathrm{mg} / \mathrm{kg}$ intake of asiatic acid [27] and $1 \mathrm{mg} / \mathrm{kg}$ of asiaticoside was fed via oral administration [43]. In fact, by giving asiaticoside of $1.00 \mathrm{~g} / \mathrm{kg}$ of the patient's body weight has proven to be non-toxic in oral application of $C$. asiatica extract [1].

\section{CONCLUSION}

C. asiatica is regarded as an important traditional herbal medicine or remedies to cure people who were suffering from different kinds of diseases such as blood pressure reductions, treat kidney diseases, or wound healing. It is widely used for feeding sources for local communities. The natural extracts can prevent oxidative damage against the free radicals, hence maintained oxidative stress and promoted human health.

Several published data that had been highlighted regarding the potential role of $C$. asiatica as natural antioxidants and antimicrobial agents are discovered and recorded. The previous studies had reported that ethanolic extract of $C$. asiatica gave a favorable yield for important biological compounds which are madecassic acid, asiatic acid, madecassoside, and asiaticoside. As antimicrobial properties, C. asiatica ethanolic extract was able to inhibit most of the pathogenic bacteria and spoilage microorganisms. For antioxidant properties, the radical scavenging properties were correlated with high phenolic compounds for $C$. asiatica. Since the $\mathrm{IC}_{50}$ value of $C$. asiatica extract has achieved between 10 to $50 \mu \mathrm{g} / \mathrm{mL}$, thus $C$. asiatica can prove as an effective antioxidant agent. 
Based on the toxicology studies by using BSLA or other experimental animals, $C$. asiatica extract has shown its wide pharmacological activities and therapeutic effect. Also, the living organisms are secured from feeding or oral administration and $\mathrm{LC}_{50}$ value are between 500 to $1000 \mu \mathrm{g} / \mathrm{mL}$, which indicate that it caused low or insignificant toxicity on the tested animals. Therefore, these data may provide essential information for future studies regarding the development of natural food preservatives by using $C$. asiatica extract as the replacement of synthetic additives which can secure consumers' health. However, more future studies need to be taken to understand the chemical and biological activities of $C$. asiatica in more detail.

\section{ACKNOWLEDGMENT}

We thank to the FRGS-RACER grant (2019-0169-103-62(RACER/1/2019/STG03/UPSI//1) and Universiti Pendidikan Sultan Idris (UPSI) for the continuous support to complete this review paper.

\section{REFERENCES}

[1] Hashim, P. (2011). Mini Review: Centella asiatica in food and beverage applications and its potential antixodiant and neuropeortective effect. International Food Research Journal, 18(4), 1215-1222.

[2] Nasution, M.Y., Restuati, M., Pulungan, A.S.S., Pratiwi, N., \& Diningrat, D.S. (2018). Antimicrobial activities of Centella asiatica leaf and root extracts on selected pathogenic microorganisms. Journal of Medical Sciences, 18(4), 198-204.

[3] Nurlaily, A., Noor-Baitee, A.R., \& Musalmah, M. (2012). Comparative antioxidant and anti-inflammatory activity of different extracts of Centella asiatica (L.) Urban and its active compounds, asiaticoside and madecassoside. Medical and Health, 7(2), 62-72.

[4] Zainol, M.K., Abd-Hamid, A., Yusof, S., \& Muse, R. (2003). Antioxidant activity and total phenolic compounds of leafs, roots, and petiole of four accessions of Centella asiatica (L.) Urban. Food Chemistry, $81,575-581$.

[5] Maisuthisakul, P., Suttajit, M., \& Pongsawatmanit, R. (2007). Assessment of phenolic content and free radical-scavenging capacity of some Thai indigenous plants. Food Chemistry, 100(4), 1409-1418.

[6] Gbolahan, B.W., Abiola, A.I., Kamaldin, J., Ahmad, M.A., \& Atanassova, M.S. (2016). Accession in Centella asiatica: Current understanding and future knowledge. Journal of Pure and Applied Microbiology, 10(4), 2485-2494.

[7] USDA-ARS. (2014). Database of Germplasm Resources Information Network (GRIN). Maryland: National Germplasm Resources Laboratory.

[8] Chew, K.K., Ng, S.Y., Thoo, Y.Y., Khoo, M.Z., Wan Aida, W.M., \& Ho, C.W. (2011). Effect of ethanol concentration, extraction time, extraction temperature on the recovery of phenolic compounds and antioxidant capacity of Centella asiatica extratcs. International Food Research Journal, 18, 571-578.

[9] Chandrika, U.G., \& Prasad-Kumarab, P.A.A.S. (2015). The relative contributions of vitamin C, carotenoids and phenolics to the antioxidant potential of fruit juices. Advances in Food and Nutrition Research, 75, 125-157.

[10] Aziz, Z.A., Davey, M.R., Power, J.B., Anthony, P., Smith, R.M., \& Lowe, K.C. (2007). Production of asiaticoside and madecassoside in Centella asiatica in vitro and in vivo. Biologia Plantarum, 51, 34-42.

[11] Alqahtani, A., Cho, J.L., Wong, K.H., Li, K.M., Naumovski, V.R., \& Li, G.Q. (2017). Differentiation of three Centella species in Australia as inferred from morphological characteristics, ISSR molecular fingerprinting and phytochemical composition. Frontiers in Plant Science, 8, 1-16.

[12] Perera, K.S., Chandrika, U.G., Salim, N., Wijepala, G.D., \& Goonetilleke, A.K. (2011). Carotenoid and mineral content of different morphotypes of Centella asiatica L. (Gotukola). International Journal of Food Science and Nutrition, 62(5), 552-557.

[13] Kormin, S. (2005). The effect of heat processing on triterpene glycosides and antioxidant activity of herbal pegaga (Centella asiatica L. urban) drink. Master, pp 1-50, 2005.

[14] Wongfhun, P., Gordon, M.H., \& Apichartsrangkoon, A. (2010). Flavour characterization of fresh and processed pennywort (Centella asiatica L.) juices. Food Chemistry, 119(1), 69-74.

[15] Jhansi, D., \& Kola, M. (2019). The antioxidant potential of Centella asiatica. Journal of Medical Plant Studies, 7(2), 18-20.

[16] Rattanakom, S., \& Yasurin, P. (2014). Review: Antibacterial, antioxidant and chemical profile of Centella asiatica. Biomedical and Pharmacology Journal, 7(2), 445-451. 
[17] Hashim, P., Sidek, H., Helan, M.H.M., Sabery, A., Palanisamy, U.D., \& Ilham, M. (2011). Triterpene composition and bioactivities of Centella asiatica. Molecules, 16(2), 1310-1222.

[18] Shukla A., Rasik, A.M., \& Dhawan, B.N. (1999). Asiaticoside-induced elevation of antioxidant levels in healing wounds. Phototherapy Research Phototherapy Research, 13(1), 50-54.

[19] Posedek, A. (2007). Natural antioxidants and antioxidant capacity of Brassica vegetables: A review. Food Science and Technology, 40(1), 1-11.

[20] Chanwitheesuk, A., Teerawutgulrag, A., \& Rakariyatham, N. (2005). Screening of antioxidant activity and antioxidant compounds of some edible plants of Thailand. Food Chemistry, 92(3), 491-497.

[21] Mustafa, R.A, Hamid, A.A., Mohamed, S., \& Abu Bakar, F. (2010). Total phenolic compounds, flavonoids and radical scavenging activity of 21 selected tropical plants. Journal of Food Science, 75(1), 28-35.

[22] Gardner, P.T., White, T.A.C., McPhail, D.B., \& Duthie, G.G. (2000). Gotu Kola (Centella asiatica): Nutritional Properties and Plausible Health Benefits. Food Chemistry, 68, 471-474.

[23] Hamid, A.A., Md-Shah, Z., Muse, R., \& Mohamed, S. (2002). Characterisation of antioxidative of Centella asiatica (L) Urban. Food Chemistry, 77(4), 465-469.

[24] Ling L.T., Radhakrishnan, A.K., Subramaniam, T., Hwee, M.C., \& Palanisamy, U.D. (2010). Assessment of antioxidant capacity and cytotoxicity of selected Malaysian plants. Molecules, 15, 2139-2151.

[25] Jaswir, I., Hassan, T., \& Mohd-Said, M.Z. (2004). Efficacy of Malaysian plant extracts in preventing peroxidation reactions in model and food oil system. Journal of Oleo Science, 53(11), 525-529.

[26] Tan, P.W., Tan, C.P., \& Ho, C.W. (2011). Antioxidant properties: Effects of solid-to-solvent ratio on antioxidant compounds and capacities of pegaga (Centella asiatica). International Food Research Journal, $18,557-562$.

[27] Pittella, F., Dutra, R.C., Junior, D.D., Lopes, M.T., \& Barbosa, N. (2009). Antioxidant and cytotoxic activites of Centella asiatica (L) Urban. International Journal of Molecular Science, 10(9), 3713-3721.

[28] Gordon, M.H. (2011). Antioxidants in Food. Berkshire: University of Reading.

[29] Hossain, M.S., Tuly, F.A., Akter, S., Arman, M.S.I., Aziz, M.A., Mahmud, M.E., Das, P., Babu, M.H., \& Islam, M.M. (2018). Determination of antiemetic, antimicrobial, anti-radical and cytotoxic activity of methanolic extracts of Centella asiatica. Plant, 6(1), 1-7.

[30] Jadil, N., Hidayati, D., Hartanti, S.R., Arasyi, B., (2016). Antioxidant activities of different solvent extracts of Piper retrofractum Vahl. using DPPH Assay. Proceeding of International Biology Conference, 1854(1), $1-6$.

[31] Nurul'azah, M.Y., Sharifudin, M.S., \& Matanjun, P. (2016). Utilization of pegaga (Centella asiatica) as potential antioxidant source in herbal ice cream, Proceedings of the Regional Conference on Sustainable Agriculture, 143-146.

[32] Pitinidhipat, N., \& Yasurin, P. (2012). Antibacterial activity of Chrysanthemum indicum, Centella asiatica and Andrographis paniculata against Bacillus cereus and Listeria monocytogenes under osmotic stress. Technical Report, 15(4), 239-245.

[33] Idris, F.N., \& Nadzir, M.M. (2017). Antimicrobial activity of Centella asiatica on Aspergillus niger and Bacillus subtilis. Chemical Engineering Transaction, 56, 1381-1386.

[34] Kalita D., \& Saikia J. (2012). Ethnomedicinal, antibacterial and antifungal potentiality of Centella asiatica, Nerium indicum and Cuscuta reflexa widely used in Tiwa Tribe of Morigaon district of Assam, India. International Journal of Phytomedicine, 4(3), 380-385.

[35] Mamtha, B., Kavitha, K., Shivananda P.G., \& Srinivasan, K.K. (2004). An in vitro study of the effect of Centella asiatica [Indian pennywort] on enteric pathogens. Indian Journal Pharmacology, 36(1), 41-44.

[36] Syahmi, A.R.M., Vijayarathna, S., Sasidharan, S., Latha, L.Y., Kwan, Y.P., Lau, L.Y., Shin, L.N., \& Chen, Y. (2010). Acute oral toxicity and brine shrimp lethality of Elaeis guineensis Jacq., (oil palm leaf) methanol extract. Molecules, 15(11), 8111-8121.

[37] Hamidi, M.R., Jovanova, B., \& Panovska, T.K. (2014). Toxicological evaluation of the plant products using brine shrimp, Artemia salina (L.) model. Macedonian Pharmaceutical Bulletin, 60(1), 9-18.

[38] Padmaja, R., Arun, P.C., Prashanth, D., Deepak, M., Amit, A., \& Anjana, M. (2002). Brine shrimp lethality bioassay of selected Indian medical plants. Fitoterapia, 73(6), 508-510.

[39] Sultan, R.A., Zafar-Mahmood, S., Azhar, Z., Ahmed, S.W., \& Mahmood. Z.A. (2014). Biological activities assessment of Centella asiatica (Linn.). Journal of Herbs, Spices and Medicinal Plants, 20(3), 319-327.

[40] Selvi, C.K. (2018). Brine shrimp lethality assay of some medicinal plants using Artemia franciscana and Artemia salina. International Journal of Science and Research, 7(3), 1901-1905.

[41] Lalisan, J.A., Nuneza, O.M., \& Uy, M.M. (2014). Brine shrimp (Artemia salina) bioassay of the medicinal plant Pseudelephantopus spicatus from Iligan city, Philippines. International Research Journal of Biological Science, 3(9), 47-50.

[42] World Health Organisations, WHO. (2011). Centella asiatica (L.) Urban., from WHO West Pacific region website: http://www.wpro.who.int/internet/files/pub/70/87a.pdf. Retrieved on October 15, 2019. 
EDUCATUM JSMT Vol. 7 No.1 (2020)

ISSN 2289-7070 / e-ISSN 2462-2451 (39-47)

https://ejournal.upsi.edu.my/index.php/EJSMT/index

[43] Gohil, K.J., Patel, J.A., \& Gajjar, A.K. (2010). Pharmacological review on Centella asiatica: A potential herbal cure-all. Indian Journal of Pharmacuetical Sciences, 72(5), 546-556. 